On the opposite page to the colour photomicrographs, a key states the colour of the different components of the tissue with the particular stain employed. Occasional helpful explanatory notes are also given.

The second part details working instructions and procedures of the various stains, each of which is supplied with a pertinent or original reference.

The last part is devoted to some commonly used processing techniques, but sectioning methods have been omitted, despite the title of this part of the book. These should be included in a future edition.

The other criticisms are few and minor. For example, the type of control to be used is not stated in plate 40 , nor in the method for periodic acid Schiff reaction for glycogen. Photomicrographs for the phosphotungstic acid haematoxylin stain (Plate 51) and the Martius Scarlet blue stain (Plate 52) are not of sufficiently high standard. The Congo red stain is excellent but a photograph of the characteristic appearance under cross polaroids could have been added with advantage.

The index is comprehensive, but the distance between the subject and the page location is sometimes too great. This could have been overcome by using leader dots.

These minor criticisms do not detract from the value of this book. The standard is high throughout and stains for bone and nerve tissue, which are often difficult to achieve, are particularly excellent. This book is not only of value to laboratory workers in training, but it will also be of great value to trainee pathologists.

\section{Manual of the International Classification of Diseases, Injuries, and Causes of Death. Volume I}

Pp. xxxiii +773 , hard cover, World Health Organization, Geneva, 1977. Sw.fr. 30; US $\$ 12$. Will be published also in French, Spanish and Russian.

John Graunt, working from the London Bills of mortality in the 17th century, was one of the first to attempt a statistical survey of diseases. The first attempts at a system classification were made a century later by Sauvages, closely followed by Linnaeus and Cullen. One hundred years later, in the middle of the last century, William Farr, the first statistician at the General Register Office of England and Wales, set about creating an international uniformity in the classification, and from 1853 the International Statistical Congress (later Institute) gave approval to the various revisions of the classification provided by Farr and d'Espine. From these developed the International Classification of Diseases (ICD), the ninth revision of which is now available.

Volume I, besides providing a historical outline of the development of the classification, includes all the tabulations of the ICD except the alphabetical list which is in Volume II.

This work is essential to everyone involved in epidemiology, and that includes most hospital clinicians who have to provide the data from their patients from which the epidemiologists work. For those in family medicine the World Organization of Colleges and Academies of General Practice have produced an officially approved modification-An International Classification of the Health Problems of Primary Care (ICHPPC) which is available from The Royal College of General Practitioners, 14 Princes Gate, Hyde Park, London SW7 1 PU - Price £2.25.

\section{Medical Education and Medical Care}

(A Scottish-American Symposium)

Papers by Alexander Bearn and Others. Edited by Gordon Mclachlan. Pp. xiv $\div 215$, illustrated, hard cover. Oxford University Press, Oxford, 1977. £6.00

1976 was the bicentennial of the Declaration of Independence of the United States of America. It was also the 250th anni- versary of the founding of the University of Edinburgh Medical School. What better occasion to hold a joint Scottish/American symposium. Those who were invited had the pleasure of hearing some very interesting papers and now the rest of us can benefit from reading them.

Like all symposia some parts are more interesting than others but different people will view each chapter differently according to their own interests in the major topics involved. For example, those interested in history will enjoy reading the chapter on the Influence of Edinburgh on American Medicine by John Z. Bowers, President of the Josiah Macy Jr Foundation, one of the co-sponsors, and the chapter on Edinburgh in the History of Medicine by Ronald H. Girdwood, Dean of Medicine at the University of Edinburgh. The Secretary of the other co-sponsor, Gordon McLachlan, also contributes an interesting chapter on the Influence of Government on Health and Medical Care, as well as providing a postscript to the whole volume.

It is, however, invidious to select different chapters for praise: all, in their own way, are excellent. The reviewer's own interest was highlighted by a couple of extracts which he would like to quote: Rosemary Stevens' comment that 'medical care is bound to have a different connotation in Britain and the U.S.A. British visitors are constantly surprised at the reluctant disorganization of medical care in America, the onus put on the consumer to select a doctor ... the assumption that the best medical care in the world is available provided you can pay for it (reviewer's italics). American visitors (to Britain) are surprised at the degree to which health services are accepted as an integral part of cultural life, and are sometimes alarmed at relatively inferior physical facilities... the folksy simplicity of some G.P. surgeries, the willingness of the middle class to sit for hours, if necessary, in cavernous and dismal outpatient departments.'

Sir John Brotherton, in his summary entitled 'Implications and Challenges', quotes Dr Mahler, the Director General of the WHO: 'Health development is not synonymous with the development of increasingly sophisticated services in medical institutions. In many countries the value of these expensive institutions can be seriously questioned if measured in terms of their impact on improving the health status of the population. No country can afford to provide every citizen with every possible form of medical technology .... it would tend to make people over-dependent on a medical aristo-technocracy.'

Few can be but fascinated, if not educated, if they read this well produced book. It would make an excellent present for a friend - or for yourself to improve the appearance and quality of your bookshelf.

\section{The Molecular Biology of Animal Viruses, Volume I}

Edited by Duebi Prosad Nayak. Pp. vii +542 , illustrated, hard cover. Marcel Dekker, New York, 1977. \$29.75.

This book is being produced in two volumes, the second of which should be available early in 1978 . Volume I contains nine excellent reviews on the following topics: (1) Symmetry in Viral Architecture; (2) Interferon; (3) The Molecular Biology of Picornaviruses; (4) Togaviruses; (5) Rhabdoviruses; (6) The Biology of Myxoviruses; (7) Paramyxoviruses; (8) Reoviruses; (9) Biology of R.N.A. Tumour viruses.

Each review is written by an authority on the subject and the book is well presented with extensive reference lists. It is unfortunate that the cumulative index is to be included in the second volume, but this disadvantage is surely outweighed by the importance of releasing this information at the earliest opportunity.

As the editor states in the preface, some of the chapters are likely to become somewhat outdated in the near future. I am 